\title{
Effects of Stress, Depression, Self-efficacy, and Social Support on Quality of Life of Community Dwelling Elderly with Chronic Diseases
}

\author{
Hee Kyung Kim \\ Professor, Department of Nursing, Kongju National University, Gongju, Republic of Korea
}

\begin{abstract}
Background/Objectives: The purpose of this study was to analyze factors having effects on the quality of life of elderly with chronic diseases.

Method/Statistical Analysis: This study targeted 113 subjects in their 60 or up, residing in M city, D metropolitan city, $\mathrm{C}$ city, and $\mathrm{G}$ city. The data were analyzed using the descriptive statistics, t-test, ANOVA, Pearson's correlation coefficient and stepwise multiple regression using the SPSS Window 23.0 program.

Findings: The stress $(\mathrm{r}=-.54, p<.001)$, and the depression and quality of life ( $\mathrm{r}=-.62, p<.001)$ of subjects showed negative correlations while the self-efficacy $(\mathrm{r}=.68, p<.001)$, and the social support and quality of life $(\mathrm{r}=.69, p<.001)$ showed positive correlations. The self-efficacy $(\beta=.39)$, social support $(\beta=.39)$, the number of diseases $(\beta=.14)$, depression $(\beta=-.18)$ and age $(\beta=.13)$ had effects on the quality of life of subjects, which showed $68.0 \%$ explanatory power.

Improvements/Applications: It would be necessary to increase self-efficacy that is confidence in their abilities, and to encourage and support elderly. In order not to get exposed to more diseases in the current state, it would be needed to seek for the measures for supporting, daily life management, and use of medication, decreasing depression, and giving a boost to live younger even when getting aged.
\end{abstract}

Keywords: Chronic disease, Elderly, Social support, Depression, Self-efficacy, Quality of life.

\section{Introduction}

Due to the rapid aging in Korea, the aged in their 65 or up which was $14.9 \%$ in 2019 is estimated to be increasing to $46.5 \%$ in 2067 . The change rate of medical expenses under health insurance for the aged in their 65 or up in 2018 was $14.7 \%$, which was $2.8 \%$ higher than the whole change rate $(11.9 \%)$. The elderly evaluate their own health status as average or pretty bad, and more and more of them regard their health status as bad as they get

\footnotetext{
Corresponding Author:

Hee Kyung Kim

Dept. of Nursing, Kongju National University, Gongju, South Korea

e-mail: hkkim@kongju.ac.kr
}

older $^{[1]}$, so that there should be efforts in health care of the elderly.

Meanwhile, as a subjective well-being that evaluates the multi-dimensional elements of physical, functional, emotional, and social well-being, and also implies the concept of happy, satisfactory, and positive emotion and spirit, the quality of life expresses the well-being and satisfaction of life ${ }^{[2]}$. Especially, in the results reviewing the preceding researches related to the quality of life of the elderly, the elderly with chronic diseases had the lower quality of life than the elderly without chronic diseases $^{[3]}$, so that there should be more researches targeting them. They have to live with their chronic diseases for the rest of their lives. And as they get older, the quality of life gets lowered by various physical diseases. 
As the factors having effects on the quality of life, the daily stress ${ }^{[4]}$, the number of chronic diseases, depression, social support as social networks ${ }^{[5]}$, and self-efficacy were presented. Once the social support was provided with the mediation of self-efficacy, the quality of life of the elderly got improved ${ }^{[3]}$. Thus, when the degree of daily stress and depression was higher, the quality of life tended to be lowered, which showed the inverse correlations between stress and quality of life, and between depression and quality of life ${ }^{[4,6]}$. When the self-efficacy is higher, the quality of life gets increased, so that it would be necessary to increase the selfefficacy. And it has been reported that the quality of life is high when the elderly perceive the receipt of social support ${ }^{[3]}$. However, there are not many researches comprehensively reviewing such factors.

The purpose of this study is to establish the basic data for the development of nursing intervention necessary for improving the quality of life through the maintenance/enhancement of health of the elderly with chronic diseases, by analyzing the relations of those variables, and revealing the influence factors on the quality of life.

\section{METHOD}

1. Subjects: The subjects of this study are the elderly in their 60 or up with chronic diseases, actively working in religious institution and senior citizens center while residing in $\mathrm{D}$ metropolitan city, $\mathrm{M}$, $\mathrm{C}$, and $\mathrm{G}$ city. To verify the fitness of the sample size, the G*Power 3.1.9.4 program was used and a significance level of .05 , effect size of .15 , verification power of .80 and 11 predictive factors were applied to the regression analysis to acquire the final number of 111 subjects. Total 113 copies were used for the final analysis.

\section{Instruments:}

2.1. Stress: This study used the BEPSI-K which was modified/complemented by Lim, et al. ${ }^{[7]}$. Total 12 items are based on the 4-point Likert scale. The higher score means the higher degree of stress. When the tool was developed, the reliability was Cronbach's $\alpha=.85$, which was .90 in this study.

2.2. Depression: This study used the Short Form Geriatric Depression Scale with 15 items, which was standardized into Korean-version short form geriatric depression scale by $\mathrm{Kee}^{[8]}$. This tool has total 15 items based on the two-point scale like 0 or
1 point. The higher score means the higher degree of depression. When the tool was developed, the reliability was Cronbach's $\alpha=.84$, which was .83 in this study.

2.3. Self-efficacy: This study used the general selfefficacy scale developed by Chen, Gully, \& Eden ${ }^{[9]}$, which was adapted by $\mathrm{Noh}^{[10]}$. This tool has total eight items based on the 5-point Likert scale. The higher sore means the higher degree of selfefficacy. In the research by Noh, the reliability was Cronbach's $\alpha=.83$, which was. 96 in this study.

2.4. Social support: This study used the scale used by $\mathrm{Kim}^{[11]}$ by modifying/complementing the MSPSS (Multi-dimensional Scale of Perceived Social Support). This tool has total 12 items based on the 5 -point Likert scale. The higher score means the higher degree of social support. When the tool was developed, the reliability was Cronbach's $\alpha=.90$, which was .94 in this study.

2.5. Quality of life: This study used the Korean-version WHO Quality of Life Short Form Scaledeveloped by Min et al. ${ }^{[12]}$, which was modified/complemented byShin ${ }^{[13]}$. This tool has total 26 items based on the 5-point Likert. The higher score means the higher degree of the quality of life. In the research byMin et al. the reliability of this tool was .90 , which was.94 in this study.

\section{Data collection \& Ethical consideration:}

Approval was acquired by the ethics committee of $\mathrm{K}$ University (KNU_IRB_2020_24). After explaining the research purpose and contents to the presidents of religious institutions and senior citizens centers in D metropolitan city, M, C, and G city, and then receiving their permission, the researcher and the trained research assistant explained the research purpose and how to fill out the questionnaire to elderly people, and then received the written consents. We collected data by reading the questions in the questionnaire to help them to complete the questionnaire. It took about 20-25 minutes to fill out the questionnaire.

Data Analysis: Using the SPSS 23.0 program, this study used the descriptive statistics like percentage for the general characteristics and the degree of variables, the t-test and ANOVA for comparing the quality of life of subjects according to the general characteristics, and the Scheffe test for post-test. This study also used Pearson correlational coefficients for the relations of variables, 
and the stepwise multiple regression for analyzing the factors having effects on the quality of life.

\section{Results}

1. General characteristics of subjects: There were total 113 elderly people with chronic diseases, and they were suffering from various types of diseases such as hypertension, diabetes, heart diseases, joint diseases, respiratory diseases, nervous diseases, thyroid gland diseases, cerebral diseases, and hearing disorder. Subjects' age was from 60 to 91 , and the mean age was $72.01 \pm 7.65$. The female elderly were more than the majority $(n=80,70.8 \%)$. The case of cohabiting with spouse was more than the majority $(n=68,60.7 \%)$. The graduation from middle school or higher was more than the majority $(n=74,66.1 \%)$. The number of mean diseases of subjects was $2.77 \pm 1.21$. The case of having two diseases was $39.4 \%$ while the case of having three diseases was shown in 27 subjects (24.8\%). Most of the cases responded to their health status as pretty good or average $(n=91,81.3 \%)$. The case of exercising regularly or sometimes was more than the majority $(\mathrm{n}=75,66.4 \%)$. In case of doing exercise, total 18 subjects $(25.4 \%)$ mostly walked everyday, and 21 subjects (30.4\%) exercised for about 60 minutes each time. The exercise hours were evenly distributed from ten minutes to 120 minutes. The case of responding to their economic status as average was more than the majority $(n=63,55.8 \%)$.

2. Degree of stress, depression, self-efficacy, social support, and quality of life of subjects: The subjects' stress scored 2.19 point out of 4 points, depression scored 0.37 point of 1 point, self-efficacy scored 3.03 point out of 5 points, social supports scored 3.54 point of 5 points, and quality of life scored 3.22 point out of 5 points [Table 1].

Table 1. Degree of stress, depression, self-efficacy, social support, and quality of life of subjects

\begin{tabular}{|l|c|c|}
\hline Variables & $\mathbf{M} \pm \mathbf{S D}$ & Range \\
\hline Stress & $2.19 \pm 0.57$ & $1 \sim 4$ \\
\hline Depression & $0.37 \pm 0.33$ & $0 \sim 1$ \\
\hline Self-efficacy & $3.03 \pm 0.96$ & $1 \sim 5$ \\
\hline Social support & $3.54 \pm 0.78$ & $1 \sim 5$ \\
\hline Quality of life & $3.22 \pm 0.64$ & $1 \sim 5$ \\
\hline
\end{tabular}

3. Differences in the quality of life according to the general characteristics: There were differences in the quality of life in the statistically-significant level according to the age $(\mathrm{F}=3.92, \mathrm{p}=.023)$, relationship with spouse $(\mathrm{t}=4.17, \mathrm{p}<.001)$, the number of diseases $(\mathrm{F}=8.82, \mathrm{p}<.001)$, occupation $(\mathrm{t}=2.61, \mathrm{p}=.010)$, health status $(\mathrm{t}=4.08, \mathrm{p}<.001)$, exercise $(\mathrm{t}=4.14$, $\mathrm{p}<.001)$, and economic level $(\mathrm{F}=11.34, \mathrm{p}<.001)$.

4. Correlations ofstress, depression, self-efficacy, social support, and quality of life in subjects: The stress $(\mathrm{r}=-.54, p<.001)$, the depression and quality of life $(\mathrm{r}=-.62, p<.001)$ of subjects showed such negative correlations while the self-efficacy $(\mathrm{r}=.68$, $p<.001)$, the social support and quality of life ( $\mathrm{r}=.69$, $p<.001$ ) showed such positive correlations [Table 2].

Table 2. Correlations of stress, depression, self-efficacy, social support, and quality of life in subjects ( $N=113$ )

\begin{tabular}{|l|c|c|c|c|c|}
\hline Variables & Stress $\mathbf{r}(\boldsymbol{p})$ & Depression $\mathbf{r}(\boldsymbol{p})$ & Self-efficacy $\mathbf{r}(\boldsymbol{p})$ & Social support $\mathbf{r}(\boldsymbol{p})$ & Job competence $\mathbf{r}(\boldsymbol{p})$ \\
\hline Stress & 1 & & & & \\
\hline Depression & $.58(<.001)$ & 1 & & & \\
\hline Self-efficacy & $-.55(<.001)$ & $-.51(<.001)$ & 1 & & \\
\hline Social support & $-.65(<.001)$ & $-.63(<.001)$ & $.52(<.001)$ & 1 & \\
\hline Quality of life & $-.54(<.001)$ & $-.62(<.001)$ & $.68(<.001)$ & $.69(<.001)$ & 1 \\
\hline
\end{tabular}

5. Factors having effects on the quality of life in subjects: To understand the factors having effects on the quality of life of subjects, this study conducted the multiple regression analysis by performing the dummy treatment on the age, spouse, number of diseases, occupation, health status, exercise, and economic status that showed the significant results in the general characteristics, and also the independent variables. Regarding the issue of multicollinearity expected in case when conducting 
the multiple regression analysis, the tolerance limit was .550 .933, which was higher than 0.1. The Variance Inflation Factors(VIF) were 1.071 1.819, which was not higher than the standard as 10 , so that there was no problem with the multicollinearity. Also, the Durbin-Watsonvalue was 2.068, so that there was no problem of autocorrelation.
In the results of analysis, the self-efficacy $(\beta=.39)$, social support $(\beta=.39)$, the number of diseases $(\beta=.14)$, depression $(\beta=-.18)$ and age $(\beta=.13)$ had great effects on the quality of life of subjects, which showed $68.0 \%$ explanatory power [Table 3 ].

Table 3. Factors having effects on the quality of life in subjects

\begin{tabular}{|l|c|c|c|c|c|}
\hline Variables & B & SE & $\boldsymbol{\beta}$ & $\mathbf{t}$ \\
\hline Constant & 1.40 & .27 & & 5.195 & $<.001$ \\
\hline Self-efficacy & .25 & .05 & .39 & 5.568 & $<.001$ \\
\hline Social support & .31 & .06 & .39 & 5.103 & $<.001$ \\
\hline Number of disease (one) & .30 & .13 & .14 & 2.363 & .020 \\
\hline Depression & -.33 & .14 & -.18 & -2.305 & .023 \\
\hline Age(70 79) & .17 & .08 & .13 & 2.196 & .030 \\
\hline $\mathrm{R}^{2}=.680 \mathrm{Adj} . \mathrm{R}^{2}=.664 \mathrm{~F}=42.431 p<.001$ & & & \\
\hline
\end{tabular}

References: Number of disease $=$ one, age $=60 \sim 69$ years

\section{Discussion}

In the results of this study, the subjects showed the inverse correlations between stress, depression and quality of life while showing the positive correlations between self-efficacy, and social support and quality of life. Such results accord with the results ${ }^{[5]}$ showing that the quality of life related to health of subjects had positive correlations with self-efficacy and social support. The daily stress and quality of life of the elderly in longterm care facilities had a negative correlation ${ }^{[4]}$, and the depression of female elderly at home showed the inverse correlation with the quality of life ${ }^{[6]}$. When the stress and depression of the elderly get higher, the quality of life could get lowered. And the social support of the elderly with disaster damage showed the positive correlation with the quality of life while the depression showed the inverse correlation with the quality of life ${ }^{[14]}$. With the mediation of resilience of the elderly, stress showed the indirect effects and partially-mediating effects on the quality of life. Therefore, it would be necessary to develop and vitalize the community health enhancement program. This study recommends to conduct a further research by adding a variable of self-efficacy with a meaning similar to resilience.

Also, the self-efficacy, social support, the number of diseases, depression, and age of subjects were the variables having effects on the quality of life, which showed $68.0 \%$ explanatory power. This was similar to the results ${ }^{[5]}$ of a study reporting that the age and selfefficacy had effects on the quality of life, and the social support had effects on the quality of life related to health with the mediation of self-efficacy.By considering Korean culture regarding family as important, this is similar to the results ${ }^{[13]}$ reporting that the family support had effects on the quality of life of the elderly. Thus, the social support from others might have very important effects on the quality of life. The effects of depression on the quality of life would be different depending on the level of social support ${ }^{[14]}$. It would be necessary to apply the nursing intervention for improving the quality of life to the self-efficacy programs, and it would be also helpful to provide the programs related to social support. The subjects are the elderly with one or more chronic diseases. Considering that the health status gets poorer when the age is higher, it would be needed to establish the support programs providing helps from family and experts, by increasing the self-care ability related to chronic diseases. The results were similar to the results ${ }^{[6]}$ of a study reporting that the depression of the female elderly at home had negative effects on the quality of life with the mediation of daily activities. It would be 
necessary to seek for the measures for lowering the depression by researching the progress of diseases when the age gets higher.

The local governments and healthcare specialists should vitalize the volunteer activity programs targeting the elderly with chronic diseases in community, and also operate the physical/psychological healthcare programs for the elderly in which the residents could actively participate.

\section{Conclusions}

To improve the quality of life of the elderly with chronic diseases in daily life, it would be necessary to increase the self-efficacy which is confidence in abilities and also to encourage and support them all the time. Also, in order not to get exposed to more diseases in the current state, it would be needed to seek for the measures for educating and supporting in relation to disease control like medical check-up, daily life management, and use of medication, decreasing the feeling of depression, and giving a boost to live younger even when getting aged. This requires not only the efforts from the elderly, but also the active development and operation of programs by their families and experts. This study suggests a further research for revealing much more factors.

\section{Ethical Clearance: Not required}

\section{Source of Funding: Self}

\section{Conflict of Interest: Nil}

\section{References}

1. Statistics Korea. 2019 Senior Statistics. [Internet] [cited 2020 March 31], 2019. Available from: http://kostat.go.kr/portal/korea/kor_nw/1/1/index. board? bmode $=$ read $\&$ aSeq $=377701$

2. Nam KM, Jung EK. The influence of social activity and social support perceived by elderly women living alone on their quality of life: Focusing on the mediating effect of depression and death-anxiety. Korean Journal of Gerontological Social Welfare. 2011; 52(6): 325-348.

3. Lee HK, Cho SH, Kim JH, Kim YK, Choo HI. Influence of self-efficacy, social support and sense of community on health -related quality of life for middle-aged and elderly residences living in a rural community. Journal of Korean Academy Nursing. 2014; 44(6): 608-616.
4. Lee KI, Lee JH. The impacts of daily stress, ego resilience, and quality of life of the elderly in long-term care institutions. Journal of the Korea Convergence Society. 2017; 8(6): 325-336.

5. Ju YJ. A path analysis for health related quality of life in elderly. Doctoral dissertation, Kongju National University, 2013. Gongju.

6. Hwang MG. The Effect of Depression BMI and Cognitive Function on Subjective Quality of Life in the Community-Dwelling Women Older Adults: Focused on the Mediating Effect of IADL and ADL. Korean Journal of Gerontological Social Welfare. 2008; 42:407-430.

7. Lim JH, Bae JM, Choi SS, Kim SW, Hwang HS,Huh BR. The validity of the Korean version of BEPSI questionnaire (revised version) as a measure of stress for foreign countries. Journal of Family Medicine. 1996: 17(1): 42-53.

8. KeeBS. A preliminary study for the standardization of geriatric depression scale short form-Korea version, Journal of Korean Neuropsychiatric Association, 1996; 35(2): 298-307.

9. Chen G, Gully MS, Eden D. Validation of a new general self-efficacy scale. Organizational Research Method. 2001; 4(1):62-83.

10. Noh JH. Why should I be thankful?: The effects of gratitude on well-being under the stress. Master's thesis. Ajou University. 2005, Suwon.

11. Kim HJ. Gender differences in influencing factors for depression in older adults. Master's degree, Korea National University of Transportation, 2014, Chungju.

12. Min SK, Lee CI, Kim KI, Shin SY, Kim DK. Development of Korean version of WHO quality of life scale abbreviated version (WHOQOL-BREF). Journal of Korean Neuropsychiatric Association. 2000; 39(3): 571-579.

13. Shin SH. A structural equation model of quality of life in nursing home residents. Doctoral dissertation, Keimyung University, 2018, Daegu.

14. Kim SB, Choi SS, Song YJ. Moderating effects of social support and social participation of the relationship between depression and quality of life of elderly victims of disaster. Korean Journal of Gerontological Social Welfare. 2019; 74(2): 9-34. 